\section{Interfacial Properties and Bottom/ Top Hardness Ratio Produced by Bulk Fill Composites in Dentin Cavities}

Letícia Virgínia de Freitas Chaves $^{1} \mathbb{D}^{\mathbb{D}}$, Samila Neres de Oliveira ${ }^{1}$, Mutlu

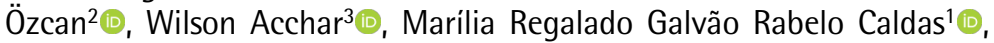
Isauremi Vieira de Assunção ${ }^{1}$ (으, Rodrigo Othávio de Assunção e Souza ${ }^{1}$, Boniek Castillo Dutra Borges ${ }^{1}$ (1)

\begin{abstract}
The aim of this study was to evaluate the bond strength, bottom/top hardness ratio, marginal adaptation, and interfacial nanoleakage of regular viscosity bulk fill composites (RVBFC) and regular viscosity traditional composites (RVTC). Two RVBFC (Filtek Bulk Fill and Aura Bulk Fill) and two RVTC (Filtek Z250XT and Aura) were assessed. Forty conical cavities $(4.8 \times 2.8 \times 4.0)$ were prepared in bovine dentin and restored with composites $(\mathrm{n}=10)$. After $24 \mathrm{~h}$ in water, marginal adaptation was evaluated by staining with a caries detector. The top and bottom surfaces of the conical restorations were stained for five seconds and the gap percentage in the composite/dentin interface was determined using digital images on a measurement program (ImageTool). The Vickers microhardness was measured and the bottom/top microhardness ratio $(B / T)$ was determined. Push-out bond strength test was performed in a universal testing machine $(0.5 \mathrm{~mm} / \mathrm{min})$ and failure modes were evaluated in a stereomicroscope $(20 \times)$. Other specimens $(n=3)$ were produced for interfacial nanoleakage evaluation. Data were analyzed using one and two-way ANOVA and Tukey's test $(\alpha=0.05)$. The gap percentage was higher in the bottom compared to the top. The B/T ratio of the Aura Bulk Fill was statistically lower than other composites. Push-out bond strength were similar among composites. The RVBFC presented lower nanoleakage than the RVTC in the bottom of the conical restoration and there was no difference among the materials in the top surfaces. In conclusion, Filtek Bulk Fill performed better than Aura Bulk Fill regarding the analyzed properties.
\end{abstract}

'Department of Dentistry, UFRN Universidade Federal do Rio Grande do Norte, Natal, RN, Brazil ${ }^{2}$ Clinic of Fixed and Removable Prosthodontics and Dental Material Science, Center of Dental Medicine, University of Zurich, Zurich, Switzerland ${ }^{3}$ Department of Physics, UFRN Universidade Federal do Rio Grande do Norte, Natal, RN, Brazil

Correspondence: Boniek Castillo Dutra Borges, Avenida Sen. Salgado Filho, 1787, 59056-000 Natal, RN, Brasil. Tel: +55-84-3215-4101. e-mail: boniek.castillo@gmail.com

Key Words: composite resins, mechanical stress, lightcuring of dental resin.

\section{Introduction}

One of the challenges in restorative dentistry is finding the balance between simple clinical protocols for restorations with composite resins and clinical longevity of restorations. (1) The traditional filling technique, consisting of multiple 2-mm composite increments, demands long chair time and increases the possibility of internal voids, which can affect mechanical properties of the composite (1). Differently, bulk-fill composites allow the placement of up to 5-mm increments, thereby saving time (2).

Flowable and regular viscosity bulk fill composites are available in the market. Flowable bulk fill composites are used as cavity bases under a covering composite. On the other hand, regular viscosity bulk fill composites have increased viscosity and most do not require a covering composite; thus, they may be used to fill the entire tooth cavity (3).

Adhesion to dentin, polymerization depth, marginal adaptation, and integrity of the hybrid layer are physical porperties that may affect the longevity of tooth restorations using regular viscosity bulk fill composites
(4). A reduced polymerization has been shown to lead to inadequate physical properties that can ultimately lead to clinical failure (5). Indeed, a weak bonding to the tooth structure increases the chance of microleakage, and thus favors adverse consequences such as postrestorative hypersensitivity, recurrent caries, marginal discoloration, and injury to the pulp (6).

Conversely, a good bond strength is synonymous with a good adaptation of the restoration to the hybrid layer. However, in high c-factor cavities, an exacerbated polymerization stress may occur, as curing shrinkage causes stress at the tooth-restoration interface. The detrimental effects of polymerization shrinkage stress include bond failure, cuspal flexure, interfacial gap, and subsequent microleakage (7).

A previous review showed that most studies do not follow the manufacturer's instructions concerning photoactivation, exceeding the recommended time and thus yielding unrealistic results about the materials (8). Concerning dentin substrate, previous investigations $(9,10)$ used a flat dentin surface, which has a low c-factor, to evaluate bond strength of bulk fill composites, not 
simulating posterior cavities, which have a high c-factor. A higher c-factor is associated with a lower bond strength, which can affect marginal integrity and lead to the formation of cracks on those restorations (11). Therefore, the push-out test can be used to measure bond strength directly on tooth cavities, in which the composite resin shrinks between internal walls causing interfacial stress during specimen fabrication (12). However, few studies evaluated mechanical properties such as bond strength, bottom/top hardness ratio, marginal adaptation, and interfacial nanoleakage of regular viscosity bulk fill composites in high $\mathrm{C}$-factor dentin cavities.

This study aimed to analyze push-out bond strength, bottom/top hardness ratio, marginal adaptation, and interfacial nanoleakage of regular viscosity bulk fill composites in dentin cavities and compare the results obtained with traditional composite resins. The null hypothesis was that there is no significant difference among the materials for all properties tested.

\section{Material and Methods}

\section{Study Design}

This in vitro study assessed the following response variables: push-out bond strength (BS), bottom/top hardness ratio $(B / T)$, marginal adaptation $(M A)$, and interfacial nanoleakage (IN). For MA and IN, a $4 \times 2$ factorial design study evaluated two factors: material [Filtek Z250XT (3M ESPE, St. Paul, MN, USA), Filtek Bulk Fill (3M ESPE, St. Paul, MN, USA), Aura (SDI, Melbourne, Victoria, Australia), and Aura Bulk Fill (SDI)], and surface (top and bottom of conical specimens). For BS and $\mathrm{B} / \mathrm{T}$, only the material variable was studied. Materials that presented different chemical compositions were selected and their compositions are listed in Table 1.

\section{Specimen Fabrication}

For B/T, MA and BS analyses, 40 specimens $(n=10)$ were fabricated. Bovine incisors were evaluated in a dissecting microscope (Stereozoom, Bausch \& Lomb, Rochester, NY, USA), being selected only the specimens free of cracks and structural defects. The samples were immersed in $0.01 \%$ thymol solution at $4{ }^{\circ} \mathrm{C}$ for one week. These specimens were prepared based in the push-out method for testing bond strength described by SousaLima et al. (12), and schematically represented in Figure 1.

The roots were removed with diamond discs (South Bay Technology, San Clement, CA, USA) coupled to a precision cutting machine (Isomet 1000; Buehler, Lake Forest, IL, USA) under water refrigeration, cut at the cementoenamel junction (CEJ). Straight, transverse cuts were made in the crowns, $4 \mathrm{~mm}$ from the $\mathrm{ACJ}$, creating a 4-mm thick disc with a central void (pulp cavity). The top and bottom surfaces of the specimens were sanded with P400 and P600 sandpapers (Labopol-21, Struers, Copenhagen, Denmark) to obtain a flat dentin surface. To optimize the space of the pulp cavity, Maxicut burs \#PM1251 (Edenta, Hauptstrasse 7, CH 9434 AU/ SG, Switzerland) were coupled to a cavity preparation standardizing machine, so that the bur penetrated perpendicularly the center of the specimen (pulp cavity), originating standard conical cavities $(4.8 \mathrm{~mm}$ top

Table 1. Materials utilized in this study

\begin{tabular}{|c|c|c|c|}
\hline Material & Manufacturer & Chemical composition (wto)* & Lot number \\
\hline $\begin{array}{l}\text { Filtek Z250 XT } \\
\text { A2 shade }\end{array}$ & $\begin{array}{l}\text { 3M ESPE, St. } \\
\text { Paul, MN, USA }\end{array}$ & $\begin{array}{l}\text { Silane treated ceramic }(75-85 \%) \text {, Bisphenol a polyethylene glycol } \\
\text { diether dimethacrylate }(5-10 \%) \text {, Diurethane dimethacrylate (5- } \\
\text { 10\%), BISGMA (1-10\%), TEGDMA }<5 \% \text {, Water }<2 \%\end{array}$ & 808770 \\
\hline $\begin{array}{l}\text { Filtek Bulk Fill } \\
\text { A2 shade }\end{array}$ & $\begin{array}{l}\text { 3M ESPE, St. } \\
\text { Paul, MN, USA }\end{array}$ & $\begin{array}{l}\text { Silane treated ceramic }(60-70 \%) \text {, Aromatic urethane dimethacrylate }(10- \\
\text { 20\%), YBF3 }(1-10 \%) \text {, UDMA }(1-10 \%) \text {, Silane treated silica }(1-10 \%), \text { DDDMA } \\
<5 \% \text {, Silane treated zirconia }<5 \% \text {, Water }<5 \% \text {, Pentanedioic acid, } \\
\text { 2,2-dimethyl-4-methylene- reaction products with glycidyl methacrylate } \\
<1 \% \text {, EDMAB }<0.5 \% \text {, Benzotriazol }<0.5 \% \text {, Titanium dioxide }<0,2 \%\end{array}$ & N874606 \\
\hline $\begin{array}{l}\text { Aura } \\
\text { E2 shade }\end{array}$ & $\begin{array}{l}\text { SDI, Melbourne, } \\
\text { Victoria, Australia }\end{array}$ & $\begin{array}{l}\text { Acrylic monomers as }(6-46 \%) \text {, Diurethane dimethacrylate (6-46\%), Triethylene glycol } \\
\text { dimethacrylate (6-46\%), 2,2-bis[4-(2-methacryloxy)ethoxy)phenyl]propane (6-46\%) }\end{array}$ & 140149 \\
\hline $\begin{array}{l}\text { Aura Bulk Fill } \\
\text { Universal shade }\end{array}$ & $\begin{array}{l}\text { SDI, Melbourne, } \\
\text { Victoria, Australia }\end{array}$ & $\begin{array}{l}\text { Acrylic monomers as }(6-46 \%) \text {, Diurethane dimethacrylate (6-46\%), Triethylene glycol } \\
\text { dimethacrylate (6-46\%), 2,2-bis[4-(2-methacryloxy)ethoxy)phenyl]propane (6-46\%) }\end{array}$ & 150710 \\
\hline $\begin{array}{l}\text { Single Bond } \\
\text { Universal }\end{array}$ & $\begin{array}{l}\text { 3M ESPE, St. } \\
\text { Paul, MN, USA }\end{array}$ & $\begin{array}{l}\text { 2-hydroxyethyl methacrylate (15-25\%), BISGMA (15-25\%), Decamethylene } \\
\text { dimethacrylate (5-15\%), Ethanol (10-15\%), Silane treated silica (5-15\%), Water } \\
\text { (10-15\%), 1,10-decanediol phosphate methacrylate (1-10\%), Copolymer of acrylic } \\
\text { and itaconic acid (1-5\%), Camphorquinone }<2 \% \text {, N,N-dimethylbenzocaine }<2 \%\end{array}$ & 582957 \\
\hline
\end{tabular}

*According to the Material Safety Data Sheet. BISGMA: Bisphenol a diglycidyl ether dimethacrylate TEGDMA: Triethylene glycol dimethacrylate YBF3: Ytterbium fluoride UDMA: Diurethane dimethacrylate DDDMA: 1, 12-dodecane dimethycrylate EDMAB: Ethyl 4-dimethyl aminobenzoate 
diameter, $2.8 \mathrm{~mm}$ bottom diameter, and $4 \mathrm{~mm}$ depth). The burs were replaced every 5 preparations. Thereby, a cavity with c-factor of 2.2 was obtained.

The cavities were restored with Single Bond Universal (3M ESPE, St. Paul, MN, USA) in the self-etch mode followed by each composite resin, according to the manufacturer's instructions. The specimens were placed on a glass slab for insertion of the adhesive system, which was photoactivated for 10 s using the Bluephase G2 LED - $1200 \mathrm{~mW} / \mathrm{cm}^{2}$ (Ivoclar Vivadent, Schaan, Liechtenstein). Then, the composites were inserted in the cavities and photoactivated according to the incremental/bulk insertion technique. A glass slab with $1 \mathrm{~mm}$ thickness was positioned on the top surface of the specimen to allow a standardized distance from the tip of the curing device to the composite/adhesive system. The restorations were finished and polished with aluminum oxide-coated abrasive discs Sof-Lex
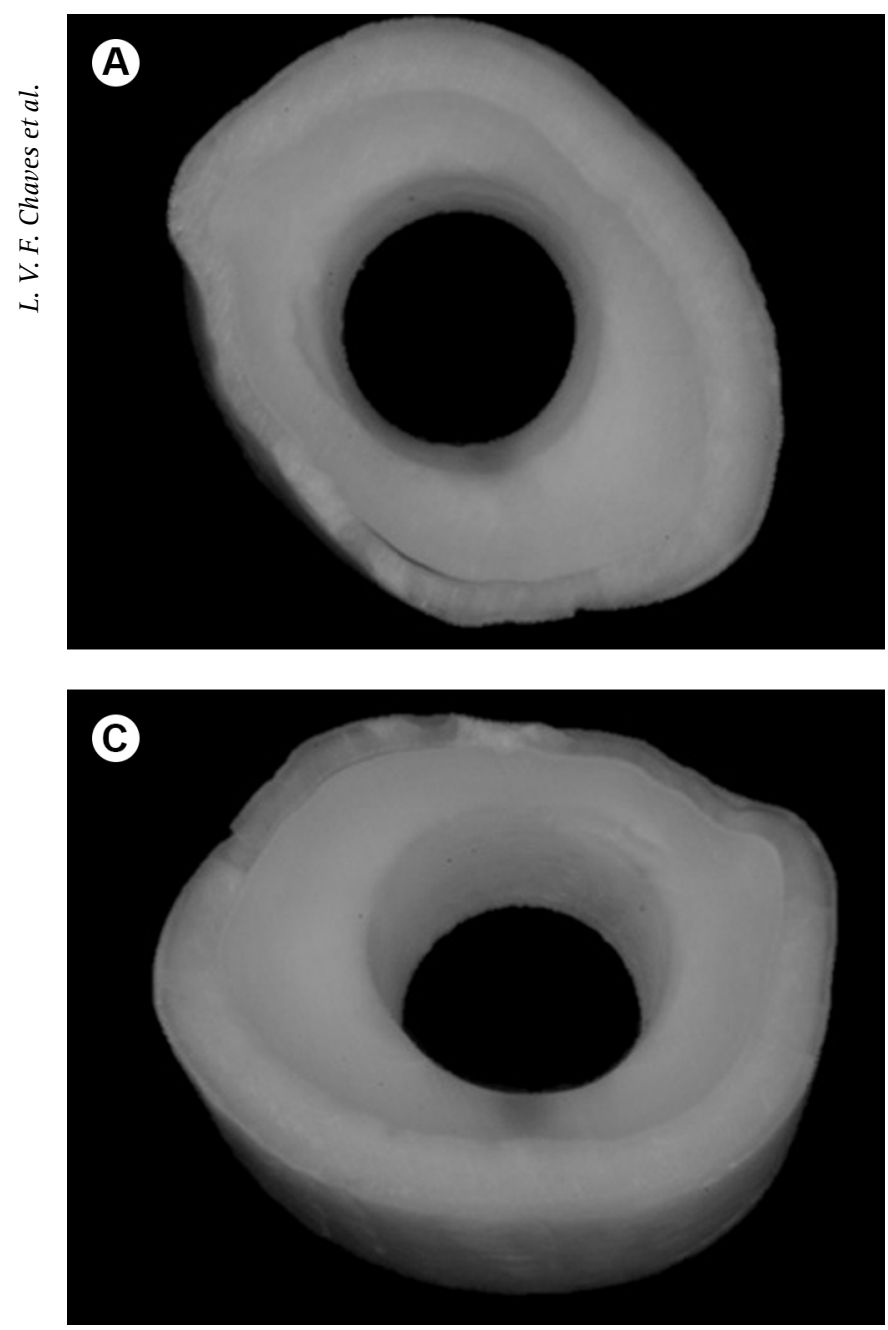

Pop On (3M ESPE) and diamond paste Diamond $\mathrm{R}$ (FGM, Joinville, SC, Brazil) in both surfaces $24 \mathrm{~h}$ after polymerization.

\section{Bottom to Top Hardness Ratio}

Bottom to top hardness ratio was obtained (12) using a Vickers microhardness tester (HV-100 Digimess, São Paulo, SP, Brazil) with a load of $50 \mathrm{~g}$ for $5 \mathrm{~s}$. Three indentations were made in each restoration surface and the average hardness value was calculated based on the measurements of the 3 values.

\section{Marginal Adaptation}

Following the method described by Souza-Junior et al (13), a solution of 1\% Acid Red dye in propylene glycol (Caries Detector, Kuraray, Osaka, Japan) was applied at the margins of the top and bottom restoration surfaces of all specimens for $10 \mathrm{~s}$. The specimens were washed with
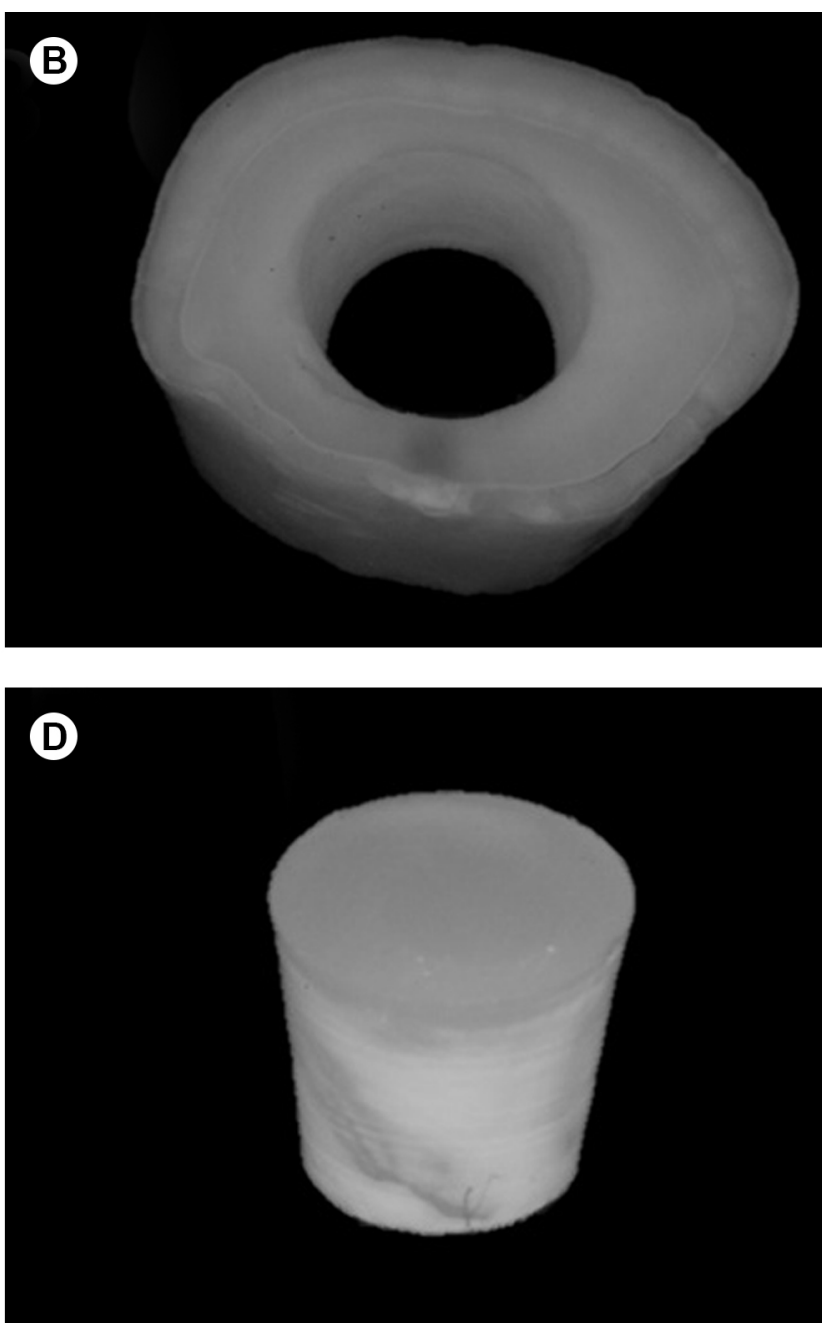

Figure 1. Adhesive failures found in the specimens: Top (A), Buccal (B), and Lingual (C) views of the cavity after debonding. The entire coneshaped composite specimen was observed (D). 
abundant distilled water for $20 \mathrm{~s}$ to remove the excess dye. Afterwards, digital images of each specimen were obtained and evaluated by a Leica MZ6 stereomicroscope with $16 \times$ magnification.

The length of the marginal gaps was measured in millimeters using the software Image Tool 2.0. The size of the gaps was calculated as a percentage of the total perimeter of the restoration. The specimens were also divided according to the presence or absence of these gaps.

\section{Push-Out Bond Strength}

To measure bond strength, a stainless-steel device was fitted to the base of a Universal Testing Machine (Zwicki-Line, Zwick/Roell, Ulm, Germany) with a gap at the center in which the specimens were placed with the smaller base facing upwards. A conic device was fitted on the machine and a compressive force with speed of $0.5 \mathrm{~mm} / \mathrm{min}$ was applied against the restoration in the center of the smaller base. The failure force was recorded in Newtons $(\mathrm{N})$ and transformed to MPa using the following equation:

$$
\mathrm{MPa}=\frac{\mathrm{N}}{\pi(\mathrm{R}+\mathrm{r}) \sqrt{\mathrm{h}^{2}+(\mathrm{R}-\mathrm{r})^{2}}}
$$

where ' $R$ ' is the radius of the larger base, ' $r$ ' is the radius of smaller base, and ' $h$ ' is the thickness of the specimen.

After the test, failure modes were analyzed in a dissecting microscope (Stereozoom, Bausch \& Lomb, Rochester, NY, USA), and classified as adhesive failure, cohesive in the composite/dentin interface, or mixed (adhesive and cohesive).

\section{Interfacial Nanoleakage}

To evaluate nanoleakage, 12 additional specimens were made $(n=3)$ as described by Sano et al. (14). After being restored, the specimens were immersed in distilled water for $24 \mathrm{~h}$ in an oven at $37^{\circ} \mathrm{C}$. Then, they were immersed in silver nitrate solution $(25 \mathrm{~g}$ of silver

Table 2. Means \pm standard deviations of the bottom/top hardness ratio $(\mathrm{B} / \mathrm{T})$ according to the type of composite

\begin{tabular}{lc}
\hline Composite & $\mathrm{B} / \mathrm{T}$ \\
\hline Filtek Z250XT & $0.80 \pm 0.07 \mathrm{a}$ \\
Filtek Bulk Fill & $0.75 \pm 0.08 \mathrm{a}$ \\
Aura & $0.75 \pm 0.11 \mathrm{a}$ \\
Aura Bulk Fill & $0.53 \pm 0.11 \mathrm{~b}$ \\
\hline
\end{tabular}

Different lowercase letters indicate significant differences between composites $(\alpha=0.05)$. nitrate crystals in $50 \mathrm{~mL}$ of distilled water and $50 \mathrm{~mL}$ of $28 \%$ ammonia hydroxide at $\mathrm{pH} 11.0$ ). The specimens remained in the dark, stored in sealed black flasks, and wrapped in aluminum paper for $24 \mathrm{~h}$. After, they were washed and immersed in photo reflective solution (Kodak, Rochester, NY, USA) for $8 \mathrm{~h}$ under fluorescent light. Once again, the specimens were washed with distilled water and then polished using sandpapers of P600-, 1200-, and 2000-grit size (Labopol-21, Struers, Copenhagen, Denmark) under refrigeration, and 0.3 and $1 \mu$ polishing pastes with felt disc. The specimens were demineralized by immersing in 37\% phosphoric acid (Super Etch, SDI, Melbourne, Victoria, Australia) for $5 \mathrm{~s}$, washed with distilled water for $30 \mathrm{~s}$, dried with absorbent paper, and then left for $24 \mathrm{~h}$ at room temperature. They were mounted on aluminum supports and examined by scanning electron microscopy (TM 3000, Hitachi, Chiyoda, Tokyo, Japan). Representative images of four quadrants were obtained for each specimen in the top and in the bottom surfaces with $40 \times$ magnification. The interfacial penetration of silver nitrate was analyzed descriptively, so that the image that represented the most prevalent pattern in the 4 quadrants was selected.

\section{Statistical Analysis}

One-way ANOVA and Tukey's post-hoc tests were used to analyze the bottom-top hardness ratio and the bond strength $(\alpha=0.05)$. Marginal adaptation was evaluated using 2-way ANOVA and Tukey's post-hoc tests $(\alpha=0.05)$. The software Assistant BETA 7.5 was used for statistical analysis. Interfacial nanoleakage was evaluated descriptively.

\section{Results}

\section{Bottom to Top Hardness Ratio}

The means of the bottom/top hardness ratio $(B / T)$ according to the type of composite and the means of bond strength according to type of composite are presented in Tables 2 and 3, respectively. Significant differences were

Table 3. Means \pm standard deviations of bond strength according to the type of composite

\begin{tabular}{lc}
\hline Composite & Bond strength (MPa) \\
\hline Filtek Z250XT & $11.12 \pm 2.1 \mathrm{a}$ \\
Filtek Bulk Fill & $10.73 \pm 1.9 \mathrm{a}$ \\
Aura & $11.40 \pm 2.8 \mathrm{a}$ \\
Aura Bulk Fill & $12.19 \pm 2.2 \mathrm{a}$ \\
\hline
\end{tabular}

Different lowercase letters indicate significant differences between composites $(\alpha=0.05)$. 
found for bottom/top hardness ratio among materials $(p<0.01$, power 0.95$)$. Aura Bulk Fill showed significantly lower values than the other materials (Table 2).

\section{Push-out Bond Strength and Failure Modes}

No significant difference was found among composites in bond strength $(p=0.07$, power 0.81 , Table 3). Only adhesive failures between adhesive and dentin were found (Fig. 2).

\section{Marginal Adaptation}

Significant differences were found for marginal adaptation among composites $(p<0.01)$ and surfaces $(p<0.01)$ (power 0.88). Comparisons among groups are shown in Table 4. Regardless of the composite, the bottom surface showed significantly higher percentage of gaps than the top surface. In both surfaces, Aura Bulk Fill showed the highest percentage of gaps while Filtek Z250 XT showed the lowest percentage.

\section{Interfacial Nanoleakage}

Nanoleakage patterns are shown in Figure 2. All composite resins showed greater nanoleakage at the bottom surface than at the top surface. Bulk fill composites showed less nanoleakage at the bottom surface than traditional composites. On the other hand, all composite resins showed similar patterns of low nanoleakage at the top surface. Silver nitrate penetrated in the dentin/adhesive interface more frequently.

\section{Discussion}

The null hypothesis tested - that there is no significant difference among the materials for all properties - was rejected. While Aura Bulk Fill showed lower percentage of well-adapted margins and lower bottom/top hardness ratio than the other composites, bond strength was similar among them. This study

Table 4. Mean \pm standard deviation of the gaps percentage according to types of composite and surfaces

\begin{tabular}{|c|c|c|}
\hline \multirow{2}{*}{ Composite } & \multicolumn{2}{|c|}{ Surface } \\
\hline & Top & Bottom \\
\hline Filtek Z250XT & $16.15 \pm 1.7 \mathrm{cB}$ & $30.72 \pm 3.6 \mathrm{cA}$ \\
\hline Filtek Bulk Fill & $19.96 \pm 1.9 \mathrm{bB}$ & $38.30 \pm 3.8 \mathrm{bA}$ \\
\hline Aura & $19.80 \pm 1.2 \mathrm{bB}$ & $42.65 \pm 5.5 \mathrm{bA}$ \\
\hline Aura Bulk Fill & $37.62 \pm 2.9 \mathrm{aB}$ & $55.74 \pm 6.7 \mathrm{aA}$ \\
\hline
\end{tabular}

Different lowercase letters indicate significant differences between the resins for the same region of the specimens. Different uppercase letters indicate significant differences between specimen regions of the same resin. evaluated bond strength in dentin cavities, which have larger adhesive area than specimens subjected to microtensile and microshear bond strength tests and might present over/underestimation of bond strength values in comparison with micro tests such as microtensile bond strength. In the push-out test, stress generated by composite polymerization is transferred directly to the adhesive interface as the composite shrinks inside the cavity in bovine dentine, which is
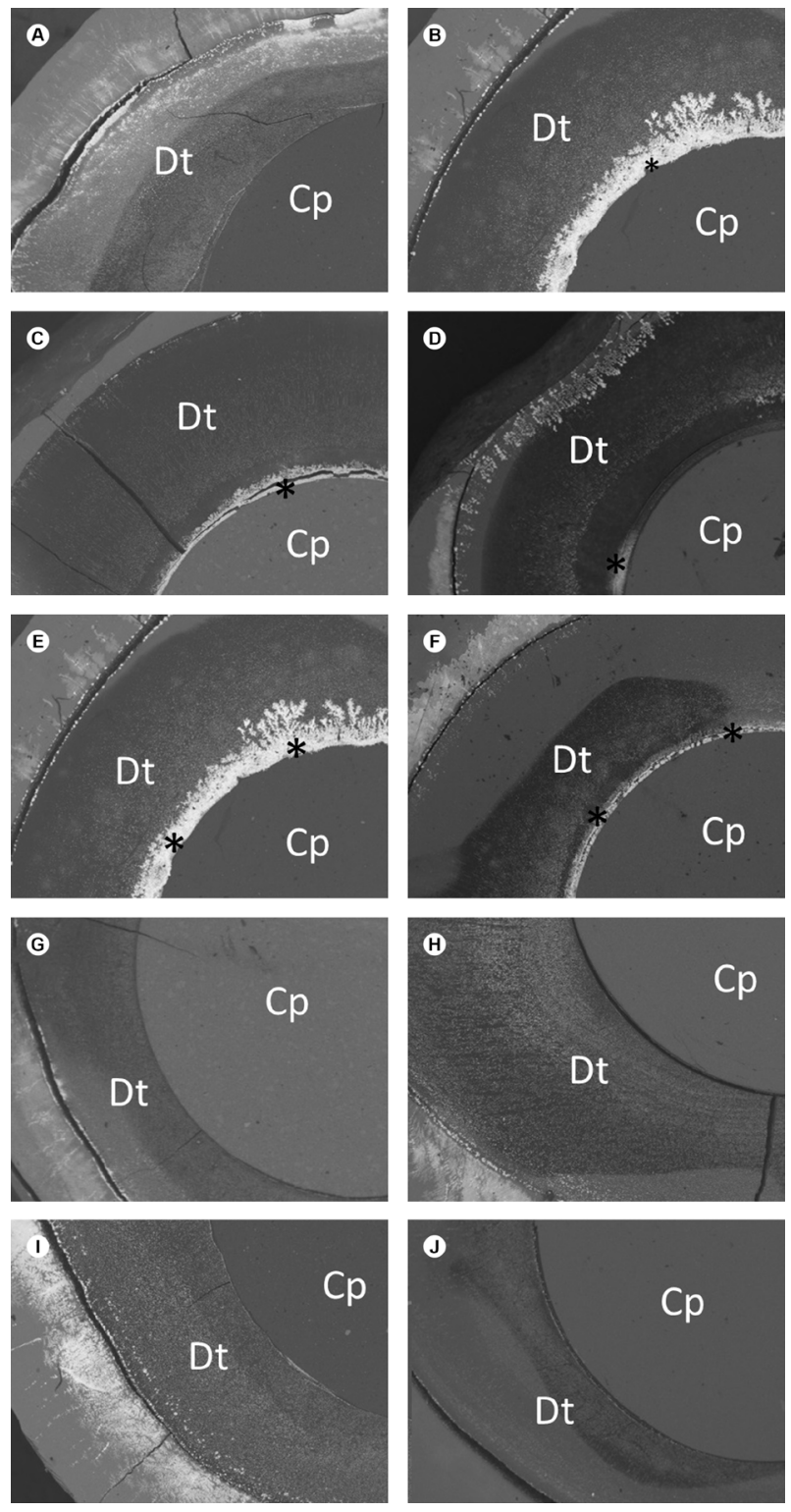

Figure 2. Increased penetration of silver nitrate $\left({ }^{*}\right)$ was found at the bottom surface (A) compared to the top surface (B) for all composites; Aura Bulk Fill (C) and Filtek Bulk Fill (D) had less nanoleakage expression (*) than their traditional correspondents Aura (E) and Filtek Z250 XT (F) at the bottom surface, whilst at the top surface Aura Bulk Fill (G) and Filtek Bulk Fill (H) showing lower nanoleakage than expression for all composites Aura (I) and Filtek Z250 XT (J). Cp: composite; Dt: Dentin. 
a good substitute of human dentin in adhesion test and was previously used to measure bond strength of bulk fill composites (12). Although the bond strength of bulk fill composites can also be analyzed using microtensile tests after filling in posterior cavities (15), specimen preparation using diamond saws to obtain the beams can transfer external stress to the tooth/ composite interface, leading to an underestimation of bond strength values. In contrast, the push-out method allows the measurement of bond strength without this external stress, so that differences found between materials are due only to their intrinsic characteristics such as chemical composition (organic matrix, photoinitiators, and filler particles), translucency, and shrinkage stress. Although slight differences between adhesive behaviors of composites might be found in some points, the bond strengths of the global interface area were similar. The fact that all specimens showed adhesive failures can strengthen the reliability of the test used, once adhesive failures commonly result from a proper distribution of forces at the specimen interface during the bond strength test (16).

However, although all composites tested presented similar adhesion behavior in dentin cavities, bottom/ top hardness ratio, marginal adaptation, and nanoleakage were different among groups. The lower bottom/top hardness ratio showed by Aura Bulk Fill in comparison with the other composites may indicate lower polymerization depth and might be related to the composition of the resin matrix. It has been observed that Bis-EMA ((2,2-bis[4-(2-methacryloxy) ethoxy)phenyl] propane) is able to restrict the mobility of UDMA (diurethane dimethacrylate) monomers and decrease their reactivity and conversion value (17). Although Aura also contains Bis-EMA and UDMA, it was polymerized in two successive 2-mm increments, differently from the single 4-mm increment done with Aura Bulk Fill. Thus, it is likely that decreased radical mobility of UDMA monomers in the presence of Bis-EMA (18) associated with light attenuation in the 4-mm increment caused the lower bottom/top hardness ratio by Aura Bulk Fill composite. In addition, the universal shade of Aura Bulk Fill might be more opaque than the other composites, which have A2 and E2 shades. However, further optical analysis would be necessary to confirm this supposition. In fact, a poorly polymerized composite resin may be associated with the presence of residual monomers, which are cytotoxic and can affect the clinical success of the restoration (18).

Other important parameters that affect clinical success of composite restorations are marginal adaptation and nanoleakage in the adhesive interface. The presence of gaps in the margins leads to the appearance of stains, recurrent caries, oversensitivity, and pulp pathologies (19). Nanoleakage is a leakage that occurs in nanometer-scale spaces, allowing the penetration of bacterial products or oral fluids across the interface, which compromises the stability of the resin-dentin bond through the hydrolytic breakdown of the adhesive resin or presence of collagen in the hybrid layer (20).

The fact that the bottom surface showed more marginal gaps and nanoleakage than the top surface may be attributed to the decreased degree of conversion of the adhesive system at the bottom of the cavity because of light attenuation, since the tip of the curing device was $4 \mathrm{~mm}$ apart from the lower surface. Light attenuation decreases the energy density that reaches the adhesive system at the bottom of the cavity, which can decrease the degree of conversion of the adhesive system (20). A poorly polymerized self-etching adhesive system, as the universal system used in this study, may affect bonding performance, since residual acidic monomers can retain their etching potential, thus jeopardizing adhesion (21) and increasing nanoleakage (22).

Aura Bulk Fill obtained the lowest percentage of adapted margins, while Filtek Z250 XT obtained the highest one, especially on the bottom surface. The decreased polymerization depth of Aura Bulk Fill associated with the probably low degree of conversion of the adhesive system at the bottom surface may have produced a weaker composite/ adhesive interface on the bottom surface, potentiated by non-converted monomers of the composite. This might have contributed with increased formation of marginal voids, favoring the occurrence of gaps in the margin (23).

Nanoleakage expression was more prevalent between the adhesive system and dentin, and at the bottom surface, which can be justified by the probably poorer polymerization of the adhesive system due to the light attenuation and reduction of energy density at the bottom of the cavity. If a poor deep polymerization of the Filtek Z250 XT, Filtek Bulk Fill, and Aura composites had been the reason for increased nanoleakage in the lower surfaces, nanoleakage should be expressed at the composite/ adhesive system interface (24). Indeed, the fact that some composites tend to debond in deep areas of preparations rather than in superficial ones (24) may also have contributed to the higher prevalence of 
nanoleakage in the bottom surface.

Although Filtek Z250 XT showed better adapted margins than the other composites, the bulk fill composites Filtek Bulk Fill and Aura Bulk Fill showed less nanoleakage than traditional composites at the bottom surface. This finding probably occurred because nanoleakage indicates the occurrence of nanospaces that are not seen with marginal adaptation analysis due to their small sizes.

Although the conventional technique to evaluate nanoleakage expression by means of 2D scanning electron microscopy image projections may be dependent on direction, position, and inclination of the chosen field-of-view, it is still been used in recently studies (25). Since our images were obtained in an only inclination of the field-of-view, discrepancies due to artifacts could be avoided. However, further investigations should be performed to analyze the mechanical properties of regular viscosity bulk fill composites in aged specimens, which we did not investigate. Also, other composites available in the market should be evaluated to verify their quality.

The tested regular viscosity bulk fill composites (Filtek Bulk Fill and Aura Bulk Fill) performed similar to or better than traditional composites (Filtek Z250XT and Aura), and Filtek Bulk Fill performed better than Aura Bulk Fill regarding bottom/top hardness ratio, marginal adaptation, and interfacial nanoleakage.

\section{Resumo}

O objetivo deste estudo foi avaliar a resistência de união, razão base/topo de microdureza, adaptação marginal e nanoinfiltração interfacial de resinas compostas bulk fill (BF) e tradicional (RT) de viscosidade regular. Duas BF (Filtek Bulk Fill e Aura Bulk Fill) e duas RT (Filtek Z250XT e Aura) foram testadas. Quarenta cavidades cônicas $(4,8 \times 2,8 \times 4,0)$ foram preparadas em dentina bovina e restauradas com os compósitos $(n=10)$. Depois de $24 \mathrm{~h}$ em água, a adaptação marginal foi avaliada por meio do corante com detector de cárie. As faces de topo e base das restaurações cônicas foram coradas por cinco segundos e a porcentagem de fendas na interface compósito/ dentina foi determinada utilizando-se imagens analisadas num programa (ImageTool). A microdureza Vickers foi mensurada e a razão base/topo de microdureza $(B / T)$ foi determinada. $A$ resistência de união por push-out foi executada numa máquina de ensaios universal $(0,5 \mathrm{~mm} / \mathrm{min})$ e o padrão de fratura avaliado num estereomicroscópio (20x). Espécimes adicionais $(n=3)$ foram confeccionados para avaliação da nanoinfiltração interfacial. Os dados foram analisados por meio de ANOVA a dois fatores e teste de Tukey $(\alpha=0,05)$. A porcentagem de fendas foi maior na base que no topo. A B/T da Aura Bulk Fill foi estatisticamente menor que os demais compósitos. A resistência de união por push-out foi similar entre os compósitos. As BF apresentaram menos nanoinfiltração que as RT na base das restaurações cônicas e não houve diferenças entre os materiais no topo. Conclui-se que a Filtek Bulk Fill comportou-se melhor que a Aura Bulk Fill considerando-se as propriedades analisadas.

\section{References}

1. Yazici A, Antonson S, Kutuk Z, Ergin E. Thirty-six-month clinical comparison of bulk fill and nanofill composite restorations. Oper Dent 2017:42:478-485.

2. Li $X$, Pongprueksa $P$, Meerbeek BV, Munck JD. Curing profile of bulk-fill resin-based composites. J Dent 2015;43:664-672.

3. Tarle Z, Attin T, Marovic D, Andermatt L, Ristic M, Tauböck TT. Influence of irradiation time on subsurface degree of conversion band microhardness of high-viscosity bulk-fill resin composites. Clin Oral Investig 2015;9:831-840.

4. Heck K, Manhart J, Hickel R, Diegritz C. Clinical evaluation of the bulk fill composite QuiXfil in molar class I and II cavities: 10-year results of a RCT. Dent Mater 2018;34:138-147.

5. Ferracane JL. Developing a more complete understanding of stresses produced in dental composites during polymerization. Dent Mater 2005;21:36-42.

6. Al-Harbi F, Kaisarly D, Bader D, Gezawi M. Marginal integrity of bulk versus incremental fill class II composite restorations. Oper Dent 2016;41:46-45.

7. De Assis FS, Lima SN, Tonetto MR, Bhandi SH, Pinto SC, Malaquias $P$, et al. Evaluation of bond strength, marginal integrity, and fracture strength of bulk- vs incrementally filled restorations. J Adhes Dent 2016;18:317-323.

8. Reis AF, Vestphal M, Amaral RC, Rodrigues JA, Roulet J, Roscoe MG. Efficiency of polymerization of bulk-fill composite resins: a systematic review. Braz Oral Res 2017;31:e59.

9. Braga $S$, Oliveira L, Rodrigues RB, Bicalho AA, Novais $V R$, Armstrong $S$, et al. The effects of cavity preparation and composite resin on bond strength and stress distribution using the microtensile bond test. Oper Dent 2018;43:81-89.

10. Ilie N, Schoner C, Bucher K, Hickel R. An in-vitro assessment of the shear bond strength of bulk-fill resin composites to permanent and deciduous teeth. J Dent 2014;4:50-55.

11. Perdigão J. Dentin bonding variables related to the clinical situation and the substrate treatment. Dent Mater 2010;26:2437.

12. Sousa-Lima RX, Silva L, Chaves LV, Geraldeli S, Alonso RC, Borges BC. Extensive assessment of the physical, mechanical, and adhesion behavior of a low-viscosity bulk fill composite and a traditional resin composite in tooth cavities. Oper Dent 2017;42:159-166.

13. Souza-Junior EJ, de Souza-Régis MR, Alonso RC, de Freitas AP, Sinhoreti MA, Cunha LG. Effect of the curing method and composite volume on marginal and internal adaptation of composite restoratives. Oper Dent 2011;36:231-238.

14. Sano H, Takatsu T, Ciucchi B, Horner JA, Matthews WG, Pashley DH. Nanoleakage: leakage within the hybrid layer. Oper Dent 1995;20:18-25.

15. Van Ende A, De Munck J, Van Landuyt K,Van Meerbeek B. Effect of bulk-filling on the bonding efficacy in occlusal Class I cavities. J Adhes Dent 2016;18:119-124.

16. Scherrer SS, Cesar PF, Swain MV. Direct comparison of the bond strength results of the different test methods: a critical literature review. Dent Mater 2010;26:78-93.

17. Alshali RZ, Silikas N, Satterthwaite JD. Degree of conversion of bulk-fill compared to conventional resin-composites at two time intervals. Dent Mater 2013;29:213-217.

18. Simi B, Suprabha B. Evaluation of microleakage in posterior nanocomposite restorations with adhesive liners. J Conserv Dent 2011;14:178-181.

19. Eick JD, Gwinnett AJ, Pashley DH, Robinson SJ. Current concepts on adhesion to dentin. Crit Rev Oral Biol Med 1997;8:306-335.

20. Maleknejad F, Ameri H, Manafi S, Chasteen J, Ghavamnasiri M. The effect of photoactivation time and light tip distance on the degree of conversion of light and dual-cured dentin adhesives. Indian J Dent Res 2013;24:225-228.

21. Das AK, Muddugangadhar BC, Amarnath GS, Garg A, Kumar U, Rao TR. Comparative evaluation of push out bond strength of a 
fiber post system using four different resin cements: an in-vitro study. J Int Oral Health 2015;7:62-67.

22. Hass V, Luque-Martinez I, Sabino NB, Loguercio AD, Reis A. Prolonged exposure times of one-step self-etch adhesives on adhesive properties and durability of dentine bonds. J Dent 2012;40:1090-1102.

23. Cebe MA, Cebe F, Cengiz MF, Cetin AR, Arpag OF, Ozturk B. Elution of monomer from different bulk fill dental composite resins. Dent Mater 2015;31:141-149.
24. Hayashi J, Shimada Y, Tagami J, Sumi Y, Sadr A. Real-time imaging of gap progress during and after composite polymerization. J Dent Res 2017;96:992-998.

25. Kaczor K, Gerula-Szymańska A, Smektała T, Safranow K, Lewusz K, Nowicka A. Effects of different etching modes on the nanoleakage of universal adhesives: A systematic review and meta-analysis. J Esthet Rest Dent 2018;30:287-298.

Received December 21, 2018 Accepted February 28, 2019 